\title{
Evaluation of Minimum Drinking Age Laws Using the National Electronic Injury Surveillance System
}

Traffic Safety Programs

Office of Program and Demonstration Evaluation 
Technical Report Documentation Page

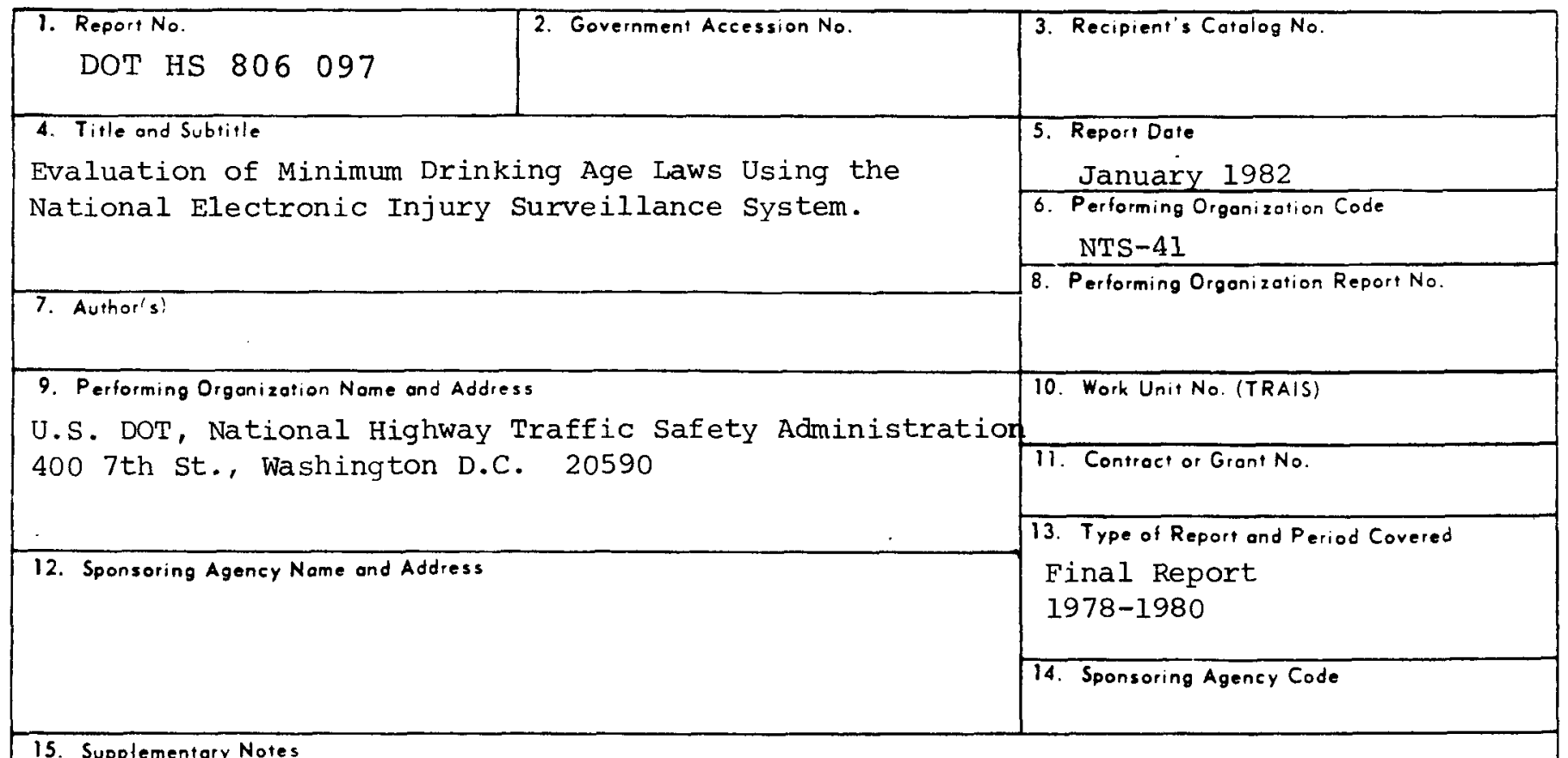

15. Supplementory Notes

16. Abstroct

This report analyzes driver injury data collected by the National Electronic Injury Surveillance System (NEISS) from October 1978 through December 1980. Nighttime driver injury rates in states with lower legal drinking age (18-19 years old) were compared to the injury rates in states with higher legal drinking age (20-21 years old). Drivers under 21 years old in states with lower legal drinking age had a significantly greater nighttime serious injury rate than in states with higher legal drinking age. There was no signigicant difference in the daytime serious injury rate of drivers under 21 year old for the two levels of legal drinking age. Drivers over 24 years old in the lower legal drinking age states had significantly greater daytime and nighttime serious injury rates than in the higher legal drinking age states: The serious injury rates for drivers between 21 and 24 years old were unaffected by legal drinking age.

It was concluded that a higher state minimu drinking age is effective in reducing the nighttime serious injury rate for driver under 21 years old. The legal drinking age had no impact on the serious injury rate for drivers 21-24 years old. The effect of legal drinking age on drivers over 24 years old was inconclusive due to significanf differences in both the daytime and nighttime serious injury rates.

\section{Koy Words}

National Electronic Injury Surveillance System, Legal Drinking Age, Driver Serious Injury Rates, Effectiveness.
18. Distribution Statement

Document is available to the U.S. public through the National Technical Information Service, Springfield, Virginia 22161

\begin{tabular}{|l|l|}
\hline 19. Security Clossit. (ol this report) & 20. Security Clossif. (of this poge) \\
Form DOT F $1700.7(8-72) \quad$ Reproduction of completed poge outhorized
\end{tabular}

\begin{tabular}{|c|c|}
\hline $\begin{array}{c}\text { 21. No. of Poges } \\
8\end{array}$ & \begin{tabular}{l} 
22. Price \\
\hline
\end{tabular} \\
\hline
\end{tabular}


METRIC CONVERSION FACTORS

Appreximate Conversions to Metric Meesures

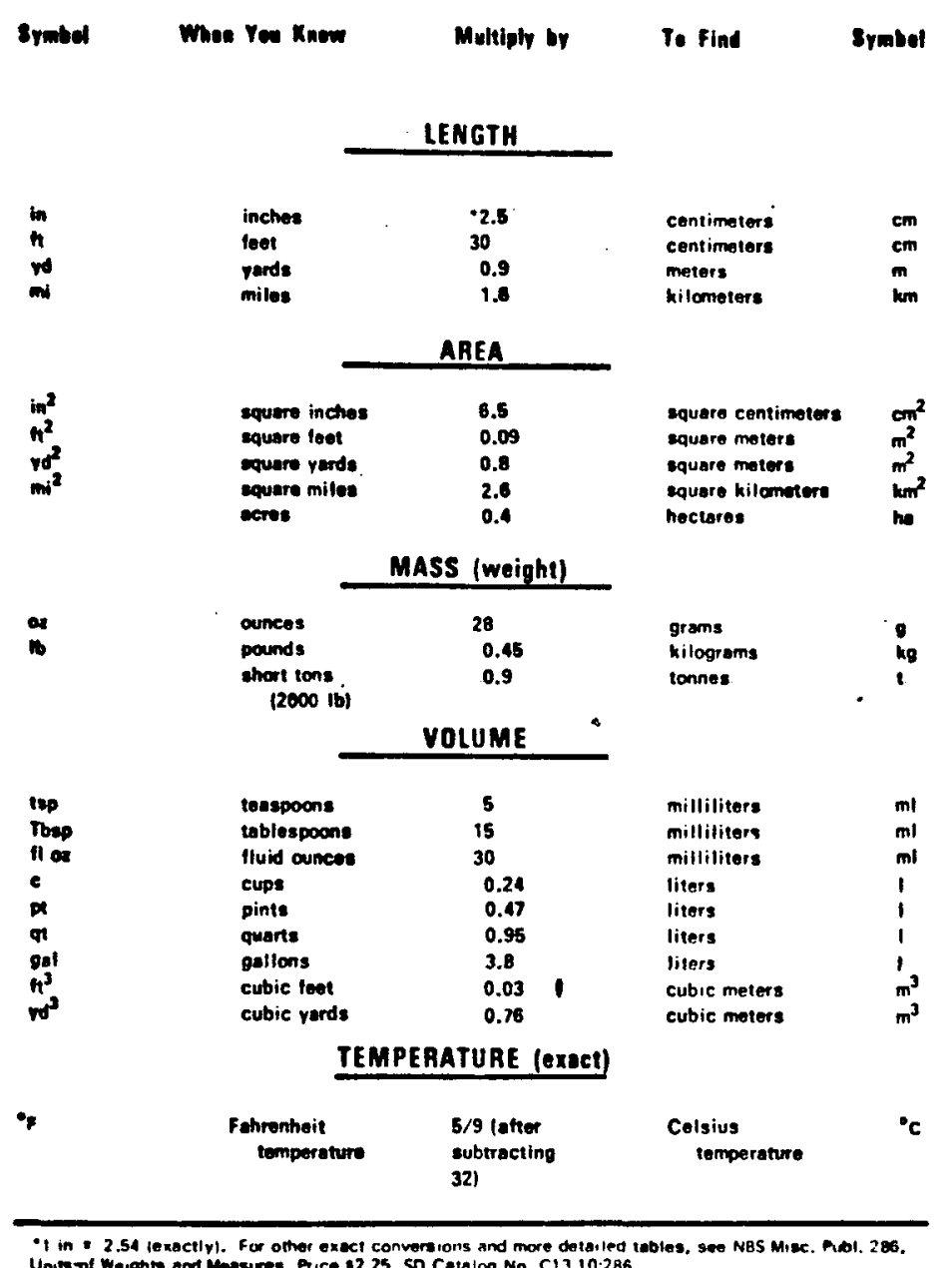

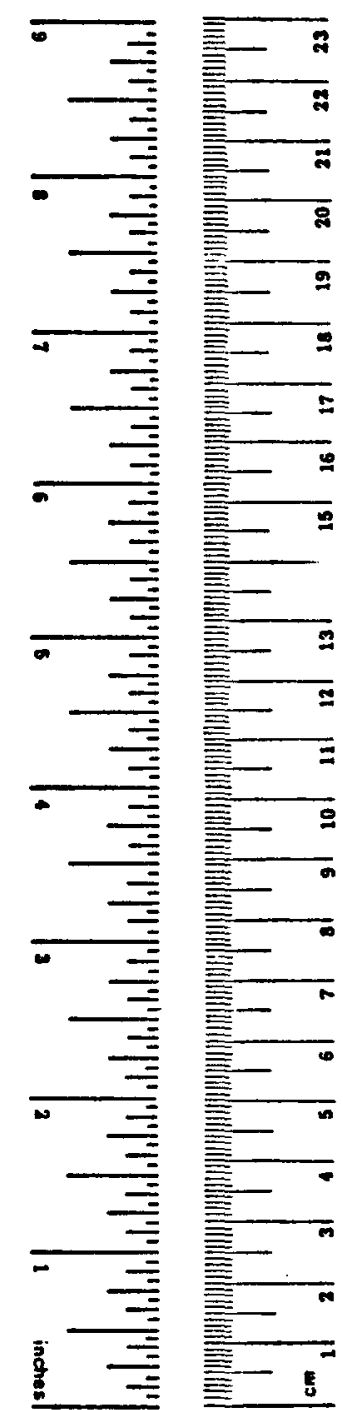

Symbol

Approximate Conversions from Metric Messures

Whon You know

Multioly by

To find

symbal

$\mathrm{cm}$
$m$
$\mathrm{~mm}$

LENGTH

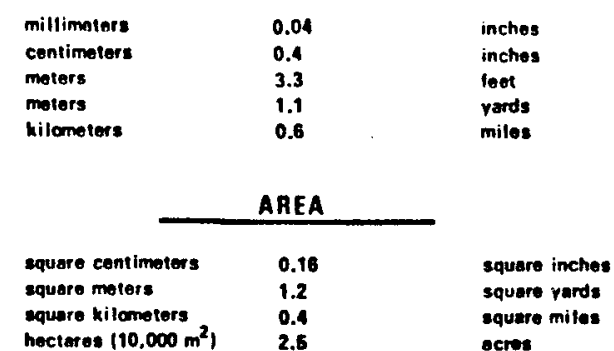

in

MASS (weight)

ing
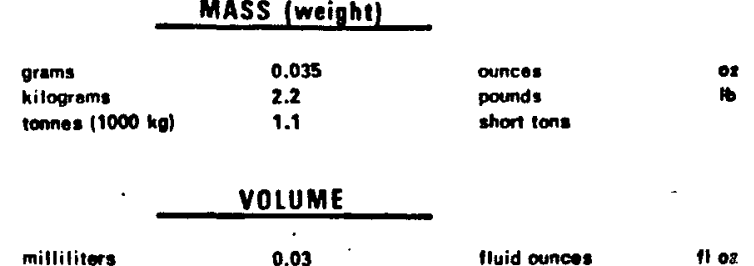

\begin{tabular}{|c|c|c|}
\hline millititers & 0.03 & fluid ouncess \\
\hline liters & 2.1 & \\
\hline liters & 1.06 & quarts \\
\hline liters & 0.26 & gallons \\
\hline $\begin{array}{l}\text { cubic meters } \\
\text { cubic moters }\end{array}$ & ${ }_{1.3}^{35}$ & $\begin{array}{l}\text { cubic leat } \\
\text { cubic yards }\end{array}$ \\
\hline
\end{tabular}

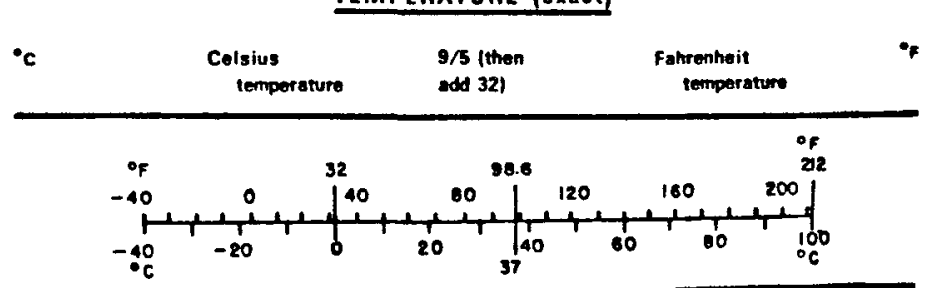




\section{EVALUATION OF MINIMUM DRINKING AGE LAWS USING THE NATIONAL ELECTRONIC INJURY SURVE ILLANCE SYSTEM}

\section{INTRODUCTION}

\section{Background}

The relationship between the minimum legal drinking age and traffic accidents has received a great deal of attention by traffic safety researchers during the past decade. Most of the previous studies have evaluated the impact on traffic safety trends in States that have recently changed the minimum drinking age law $(1,2,3,4)$. These studies have generally concluded that raising the legal drinking age has reduced accident involvement, particularly among young male drivers during the nighttime.

These legal drinking age evaluations relied on police-reported accidents as the primary source of data. Since a portion of injury accidents may not be reported to the police, using another independent data system to evaluate the impact of minimum drinking age laws could further validate the conclusions made in prior drinking age law studies. In addition, a multi-State evaluation encompassing States with stable drinking age laws along with States that have raised the legal drinking age should be very useful in determining the impact of minimum drinking age laws.

Hospital emergency room accident injury records can be used as an additional source of data due to their completeness and high quality. Most non-minor accident injuries are treated in a hospital emergency room. In addition, emergency room personnel are highly skilled in identifying, diagnosing, and evaluating accident injuries and severities. Thus, a statistical sample of hospital emergency room records could be used to evaluate the impact of legal drinking age nationwide, rather than at the statewide level, as was done in prior evaluations.

\section{Objectives}

The purpose of this study is to determine the impact of legal drinking age laws by comparing the nighttime driver injury rate in States with "low" minimum drinking age to the driver injury rate in States with "high" minimum drinking age. Nighttime driver injury rate was used as an indicator of alcohol involvement in accidents. The daytime driver injury rate was used as a control to assess the significance of observed differences in nighttime driver injury rates.

The National Electronic Injury Surveillance System (NEISS), maintained by the Consumer Product Safety Commission (CPSC), collects motor vehicle accident data reported by a nationwide statistical sample of hospital emergency rooms. The National Highway Traffic Safety Administration (NHTSA) has sponsored and has access to computerized data collected by NEISS from October 1978 through December 1980 on injurjes occurring in moving motor vehicle accidents. 
Table 1 lists the 35 States that report to NEISS along with the number of NEISS hospitals and the minimum legal drinking age for distilled spirits in each State. As indicated in the table, nine States raised the legal drinking age during the study period.

Driver injury severity data was tabulated for day (4 a.m. -8 p.m.) and night ( 8 p.m. -4 a.m.) arrivals at NEISS hospital emergency rooms. The NEISS States with a lower legal drinking age (18 or 19 years old) were compared with the NEISS States having a higher legal drinking age (20 or 21 years 01d). Twoyear drinking age periods were used to clearly delineate the effect of legal drinking age laws on driver injury severity. There were five States (I11inois, Massachusetts, Michigan, Nebraska, New Hampshire) that changed from the low legal drinking age group to the high legal drinking age group. Each of these States were put into the appropriate legal drinking age category throughout the October 1978-December 1980 time period.

Three driver age groups were evaluated for impact: under 21 years old, 21 to 24 years old, and over 24 years old. These groups should exhibit different degrees of sensitivity to legal drinking age. The youngest group should be most affected, while the oldest group should be least affected by different legal drinking age levels.

Unfortunately, NEISS does not collect data on alcohol consumption for traffic accident victims. Therefore, the relationship of legal drinking age and alcohol involvement to driver injuries could not be directly determined using the NEISS file. 
TABLE 1

NEISS States and Legal Drinking Age

STATE

Alabama
Arkansas
Arizona
California
Colorado
Connecticut
Florida
Georgia
Hawaii
Idaho
Illinois
Indiana
Iowa
Kansas
Maryland
Massachusetts
Michigan
Minnesota
Mississippi
Missouri
Montana
Nebraska
New Hampshire
New Jersey
New York
North Carolina
Ohio
Oklahoma
Oregon
Pennsylvania
Tennessee
Texas
Virginia
Washington
Wisconsin

NEISS HOSPITALS

1

1

3

6

1

1

2

1

1

4

1

3

1

1

2

5

3

1

2

1

1

1

1

3

2

1

2

6

2

3

1

1
LEGAL DRINKING AGE

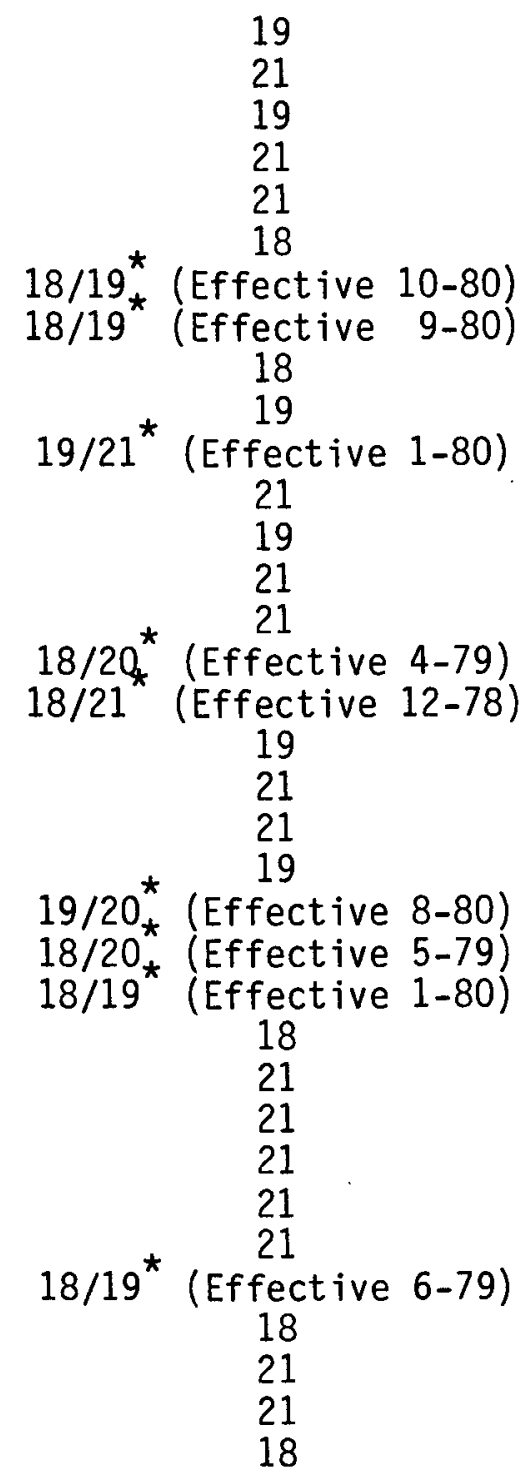

* Raised legal drinking age 


\section{DATA ANALYSIS}

\section{Injury Severity}

Every accident victim in a NEISS hospital emergency room is given an injury severity rating based on the body part affected and whether the patient is treated and released, hospitalized, or dead on arrival. NEISS uses 8 categories of increasing severity as shown in Table 2. A more commonly used motor vehicle injury rating system is the Abbreviated Injury Scale (AIS). Since April 1980 NEISS has expanded its data collection to include the AIS code for each motor vehicle injury. Thus, since only nine months of AIS injury data were available, as compared with 27 months of data with NEISS injury ratings, the NEISS injury severity scale was used exclusively to analyze driver injury rates.

\section{TABLE 2}

\section{NEISS Injury Severity Ratings}

Severity

1

2

3

4

5

6

7

8
Examples of Injuries

Mild injuries to small areas, for example, sprained foot Contusion to lower trunk; dislocated arm, hand puncture, non-hospitalized poisoning

Arm fracture, sprained neck

Finger crushing, head area laceration, punctured eye Concussion, fractured head/neck, ingested foreign object Amputations, anoxia, head crushing, hospitalized poisoning All hospitalized cases of severity 6

All deaths

\section{Nighttime Driver Injury Severity}

The proportion of serious injuries (severity $=4$ or higher) occurring at night for drivers in the three age groups is shown in Table 3 for the low (18-19 years old) and high (20-21 years old) legal drinking age categories. Injuries with unknown severity were excluded. 
TABLE 3

\section{Nighttime Driver Injuries}

\section{NEISS 1978-80}

Driver

Age

Under 21

$21-24$

Over 24
Lega 1

Drinking Age

Low (18-19)

High (20-21)

Low (18-19)

High (20-21)

Low $\quad(18-19)$

High $(20-21)$
Total

Injuries

912

841

$637^{\circ}$

593

1,433

1,272
Serious Serious/Total Injuries Injuries/Injuries

364

302

.399

.359

233

229

.366

.386

551

431

The drivers under 21 years old had a significantly higher (at the 95 percent confidence level) rate of serious injury at the lower legal drinking age than at the higher drinking age. This was also the case for the group of drivers over 24 years old. There was no significant difference between the serious injury rates at the two levels of legal drinking age for the drivers between 21 and 24 years $01 d$.

Daytime Driver Injury Severity

The rate of serious injury for drivers taken to the emergency room during the daytime hours is shown in Table 4. The age groups and legal drinking age levels that were used for nighttime driver injuries were also used for daytime driver injuries.

TABLE 4

\section{Daytime Driver Injuries}

\section{NEISS 1978-80}

Driver

Age

Under 21

21-24

Over 24
Legal

Drinking Age

Low (18-19)

High (20-21)

Low $(18-19)$

High $(20-21)$

Low (18-19)

High $(20-21)$
Total

Injuries

1,746

1,639

1.357

1,084

4,321

3,574
Serious

Injuries

512

449

389

282

1,275

962
Serious/Total

Injuries/Injuries

.293

.274

.287

.260

.295

.269 
The serious injury rate at the lower legal drinking age was not significantly different from the serious injury rate at the higher legal drinking age for drivers under 21 years old and for drivers 21 to 24 years old. For drivers over 24 years old, the serious injury rate at the lower legal drinking age was significantly greater than the serious injury rate at the higher legal drinking age.

Analys is

The difference in serious injury rate between the low and high legal drinking age levels is summarized in Table 5 .

\section{TABLE 5}

\section{Difference In Serious Injury Rate Between Low and High Legal Drinking Age}

Driver Age

Under 21

$21-24$

Over 24 $\underline{\text { Day }}$

No significant difference

No significant difference

Rate at Low Legal Drinking Age significantly greater
Night

Rate at Low Legal Drinking Age significantly greater

No significant difference

Rate at Low Legal Drinking Age significantly greater

Thus, the legal drinking age level had a significant impact on the serious injury rate for drivers under 21 years old during the nighttime (treatment) period, but had no impact on the serious injury rate during the daytime (control) period. Legal drinking age did not impact the serious injury rate for drivers 21-24 years old during either the treatment or control time periods. The impact of legal drinking age on serious injury rate for drivers over 24 years old was significant during both the treatment and control periods. 


\section{I. CONCLUSIONS}

The results of the data analysis clearly show that driver accident victims under 21 years old treated at NEISS hospital emergency rooms at night have a significantly greater likelihood of sustaining a serious injury in a State with a legal drinking age under 20 years old than in a State with a legal drinking age of 20 or 21 years old. Drivers between 21 and 24 years old in States with a lower drinking age have nearly the same chance of incurring a serious injury as those in States with a higher drinking age. A driver over 24 years old is more likely to be seriously injured at all times of the day if the injury occurred in a State with a low legal drinking age rather than in a State with a high legal drinking age.

Therefore, the NEISS data suggests that a higher State minimum drinking age is effective in decreasing the chances of suffering a serious injury for young drivers under 21 years old. The data for older drivers lover 24 years old) was inconclusive in assessing the effectiveness of higher state legal drinking age in reducing the rate of serious injury since both the nighttime and daytime injury rates were impacted by legal drinking age. It is possible that the difference in injury rate for older drivers between the two groups of States may be due to inherent characteristics in the older driver population rather than the effect of legal drinking age.

Finally, the State minimum drinking age law had no impact on the serious injury rate for drivers between the ages of 21 and 24 years, as expected. 


\section{REFERENCES}

1. Douglas. R.L., Filkins, L.D., and Clark, F.A., The Effect of Lower Legal Drinking Age on Youth Crash Involvement, September 1974, D0T-HS-801213.

2. Maxwe 11, D.M., Impact Analys is of the Raised Legal Drinking Age in Illinois, December 1981, NHTSA TechnicaT. Note (in print).

3. Wagenaar,A.C., Effects of the Raised Legal Drinking Age on Motor Vehicle Accidents in Michigan, HSRI Research Review, January-February 1981.

4. Williams, A.F., Zador, P.L., Harris, S.S., and Karpf, R.S., The Effect of Raising the Legal Minimum Drinking Age on Fatal Crash Involvement, Insurance Institute for Highway Safety, June 1981. 